\title{
541 静的解析による変位分布を用いた動的非線形方程式の低次元化
Deriving of Reduced-Order Nonlinear Equations by using a Distribution of Displacements by Static Equation

\author{
○正 原田 晃（長崎大）
}

Akira HARADA, Nagasaki University, 1-14, Bunkyo-machi, Nagasaki

\begin{abstract}
This paper presents a procedure to derive reduced-order nonlinear equations using a projection onto a sub-space which includes solutions of whole-space equations in approximation. The sub-space is defined by vectors that are obtained by decomposing solution vectors of static nonlinear finite element (FE) equations on which equivalent inertia force is acting. Even though we consider a nonlinear vibration, it has verified that there are moments that assuming accelerations are almost proportional to displacements is not so reckless. Thus, solution vectors of static FE equations are able to regard as approximate solutions of dynamic FE equations at that particular moments.
\end{abstract}

Key Words : Reduced-Order Model, Nonlinear Vibration, Finite-Element Method

A1. ば め に

本研究では解析対象に制限無く超低自由度モデルを 得られる手法の確立を目指す. 既報において, 慣性力 に相当する外力が作用する静的有限要素法方程式の解 を分解することにより得られるべクトルで定義される 部分空間へ写像することにより, 系の特徴をほとんど 損なうことなく超低自由度モデルを得ることが可能で あることが示された，本報では，既報で明らかにされ ていなかった, 静的方程式で用いる等価慣性力のパラ メータとしての振動数と動的方程式を解くことにより 得られる周期運動の振動数との関係について, 一定曲 率を有する両端固定はりを対象として検証する.

\section{A2. 静的等価慣性力モデルと動的モデル}

本報で解析の基準となる動的有限要素法方程式およ び部分空間を求めるための静的有限要素法方程式は

$$
\begin{array}{r}
\mathbf{M} \ddot{\mathbf{V}}+\left(\mathbf{K}_{L}+\mathbf{K}_{N L}(\mathbf{V})\right) \mathbf{V}=\mathbf{0} \\
\left(\mathbf{K}_{L}+\mathbf{K}_{N L}\left(\mathbf{V}^{*}\right)\right) \mathbf{V}^{*}=\omega^{* 2} \mathbf{M} \mathbf{V}^{*}
\end{array}
$$

であり，上付きの*は動的方程式に依存しない静的方程 式独自の変数であることを示す. 式(A1)を用いて変位 と加速度の比 $\ddot{V}_{i} /-V_{i}$ を計算したところ, 図A 1 のよう にその標準偏差は明確な極小值を示すことが判明した。 その時刻に扔ける $\ddot{V}_{i} /-V_{i}$ の平方根を $\omega_{L 1}+\omega^{s}$, 変位 を $\mathbf{V}^{s}\left(\Delta \omega^{s}\right)$ とすると, 式(A2)において $\omega^{*}=\omega_{L 1}+\Delta \omega^{s}$ として得られた $\mathbf{V}^{*}\left(\Delta \omega^{s}\right)$ は, 図A2 のように $\mathbf{V}^{s}\left(\Delta \omega^{s}\right)$ とよく一致している. このことから, 静的方程式中の 振動数は, 非線形振動ではあるが, 变位と加速度の比 がほぼ一定となる時刻の瞬間的な振動数に対応してい るといえる.

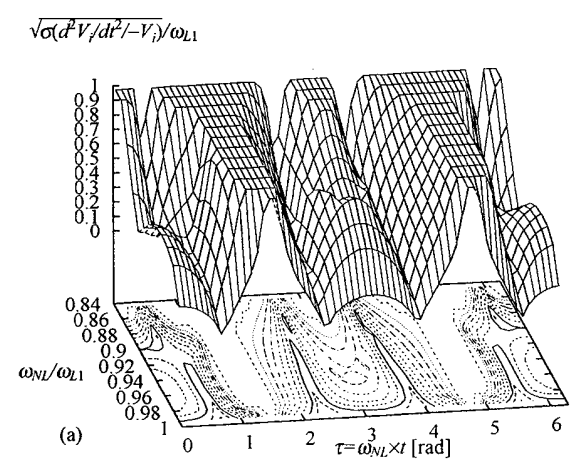

Fig. Al Standard devieation of $\ddot{V}_{i} /-V_{i}$.

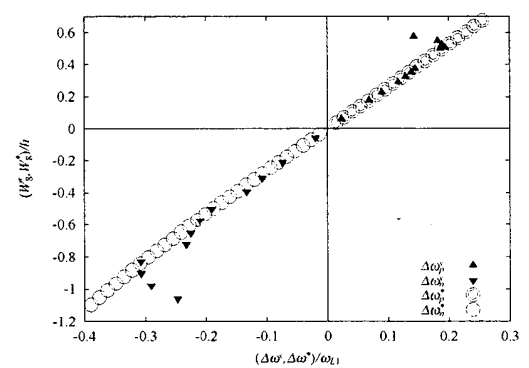

Fig. A2 Relation bitween $\mathbf{V}^{s}\left(\Delta \omega^{s}\right)$ and $\mathbf{V}^{*}\left(\Delta \omega^{s}\right)$.

\section{A3. ま と め}

本研究において, 静的方程式で用いる等価慣性力の パラメータとしての振動数と動的方程式を解くことに より得られる周期運動の振動数との関係は, 少なくと も本報で扱った対象に対しては, 明らかになったとい える. 
Table 1 Specification of the beams.

\begin{tabular}{cl}
\hline Length & $L=0.313[\mathrm{~m}]$ \\
Radius & $R=10[\mathrm{~m}]$ \\
Width & $b=30.5 \times 10^{-3}[\mathrm{~m}]$ \\
Height & $h=0.6 \times 10^{-3}[\mathrm{~m}]$ \\
Boundary Condition & Clamped-Clamped \\
Number of Element & 16 \\
Young's Modulus & $E=210[\mathrm{GPa}]$ \\
Density & $\rho=7870\left[\mathrm{~kg} / \mathrm{m}^{3}\right]$ \\
\hline
\end{tabular}

\section{1.はじめに}

従来，幾何学的非線形性を考慮した連続体の非線形 振動に関する研究は数多くなされており ${ }^{(1)}$, 解析的手 法と FEMに代表される数值的手法を組み合わせた手 法も幾つか提案されている(2)(3). しかし, それらの手法 では, 超低自由度モデルが得られる対象は限定される. そこで, 本研究では解析対象に制限無く超低自由度モ デルを得られる手法の確立を目指す。既報 ${ }^{(4)(5)(6)(7)(8)} に$ おいて，慣性力に相当する外力が作用する静的有限要 素法方程式の解を分解することにより得られるべクト ルで定義される部分空間へ写像することにより, 系の 特徴をほとんど損なうことなく超低自由度モデルを得 ることが可能であることが示された. しかし, 静的方 程式で用いる等価慣性力のパラメータとしての振動数 と動的方程式を解くことにより得られる周期運動の振 動数との関係は明らかではなかった. そこで本報にお いては, 一定曲率を有する両端固定はりを対象とし, 両者の関係について検証する.

\section{2. 静的等価慣性力モデルと動的モデル}

本報で用いる解析モデルの諸元, 解析の基準となる 動的有限要素法方程式および部分空間を求めるための 静的有限要素法方程式を, それぞれ, 表1,式(1),(2)に 示す.

$$
\begin{gathered}
\mathbf{M} \ddot{\mathbf{V}}+\left(\mathbf{K}_{L}+\mathbf{K}_{N L}(\mathbf{V})\right) \mathbf{V}=\mathbf{0} \\
\left(\mathbf{K}_{L}+\mathbf{K}_{N L}\left(\mathbf{V}^{*}\right)\right) \mathbf{V}^{*}=\omega^{* 2} \mathbf{M} \mathbf{V}^{*}
\end{gathered}
$$

$\mathbf{M}, \mathbf{K}_{L}, \mathbf{K}_{N L}$ は, それぞれ, 質量マトリクス, 線形剛性 マトリクス, 非線形剛性マトリクスであり, Vは節点 量ベクトルであり, 各節点 $i$ の接線方向変位 (面内変 位) $U_{i}$, 曲率半径方向変位 (面外変位) $W_{i}$, たわみ角 $\theta_{i}$ から構成されている. また, 上付きの*は動的方 程式に依存しない静的方程式独自の変数であることを 示す.

既報において, 式(1)によって得られた変位分布と式 (2)によって得られた変位分布は, 応答レベルが同程度 であれば, 定性的にはよく一致していることが確認さ れている. そのことから, 非線形振動においても変位 と加速度の比の空間分布が一定に近い瞬間があるので
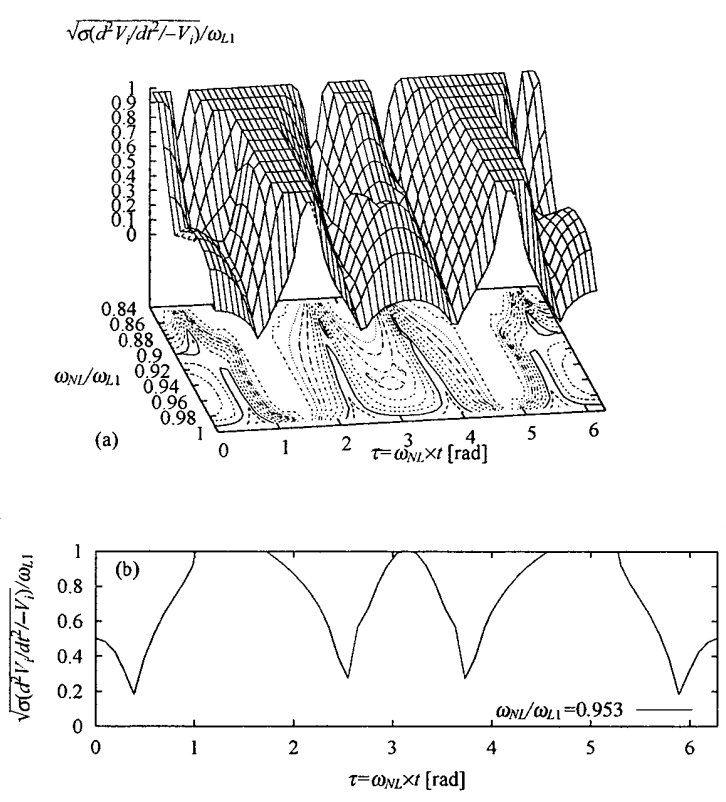

Fig. 1 Standard devieation of $\ddot{V}_{i} /-V_{i}$.
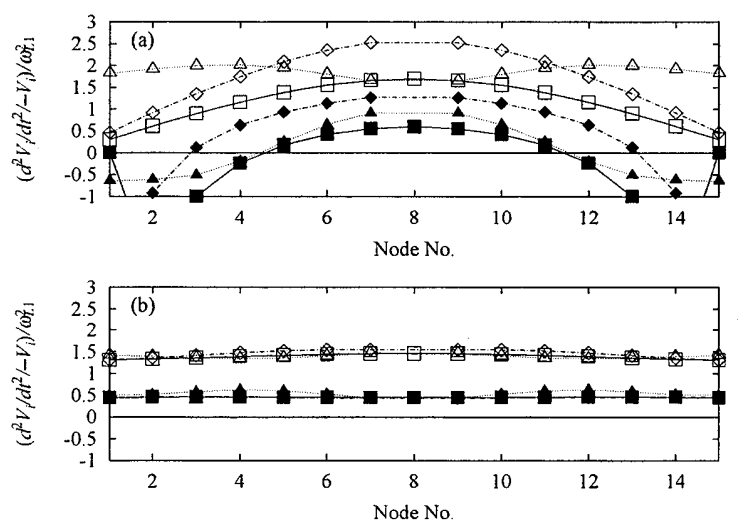

Fig. 2 Distribution of $\ddot{U}_{i} /-U_{i}$ (triangle), $\ddot{W}_{i} /-W_{i}$ (square) and $\ddot{\theta}_{i} /-\theta_{i}$ (rhombus), at $\omega_{N L} / \omega_{L 1}=$ 0.872, (a):hollow: $\tau=\tau_{\max }$, solid: $\tau=\tau_{\min }$, (b):hollow: $\tau=\tau_{p}^{s}$, solid: $\tau=\tau_{n}^{s}$.

はないかと推測される. そこで, 式(1)を用いて, 周期 運動中の各節点における変位と加速度の比, $\ddot{V}_{i} /-V_{i}$, を計算した. 線形振動状態であれば $\ddot{V}_{i} /-V_{i}$ は正の定数 となり, 運動の周期から求まる角振動数の二乗と一致 する. 図1に $\ddot{V}_{i} /-V_{i}$ の標準偏差を示す. 図1-(a)は全体 図であり, 図1-(b) は $\omega_{N L} / \omega_{L 1}=0.953$ における断面図 である. はり中央の面外変位 $W_{8}$ は $\tau=0$ において最大 值を示し, $\tau=\pi に$ にいて最小值を示している. 図から, $\tau=0 \pm \Delta \tau_{p}$ および $\tau=\pi \pm \Delta \tau_{n}$ において極小值を示して いることがわかる. また, どの非線形固有角振動数に おいても $\left(\pi+\Delta \tau_{n}\right)-\left(0+\Delta \tau_{p}\right)$ と $\left(\pi-\Delta \tau_{n}\right)-\left(0-\Delta \tau_{p}\right)$ の值はほぼ $\pi$ を示している. そこで, $W_{8}$ が最大, 最小 となる $\tau_{\max }=0, \tau_{\min }=\pi$ 扰よび $\ddot{V}_{i} /-V_{i}$ の標準偏差が極 小值をとる $\tau_{p}^{s}=0+\Delta \tau_{p}, \tau_{n}^{s}=\pi+\Delta \tau_{n}$ における $\ddot{V}_{i} /-V_{i}$ の分布について詳しく調べてみる. 


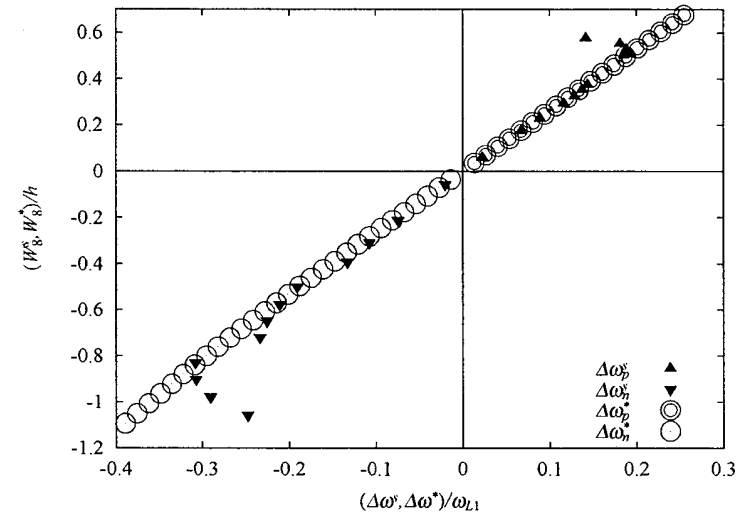

Fig. 3 Relation bitween $\Delta \omega^{s}$ and $W_{8}^{s}$, and between $\Delta \omega^{*}$ and $W_{8}^{*}$.

四2に， $\tau_{\max }, \tau_{\min }$ および $\tau_{p}^{s}, \tau_{n}^{s}$ における変位と加速 没し人比を示す. 図から, $\tau_{p}^{s}, \tau_{n}^{s}$ においては変位と加速度 の比はほぼ一定值であることがわかる. また，その比 率は $\tau_{p}^{s}$ におては線形固有角振動数の二乗よりも大 きく，祝においては小さいことがわかる，これは， $\tau_{p}^{s}$ つまり面外変位が全体的に正の領域にあるときには漸 硬ばね特性を示し， $\tau_{n}^{s}$ つまり面外変位が全体的に負の 領域にあるときには漸軟ばね特性を示す，振動の非対 称性に対応しているといえる.この $\tau_{p}^{s}, \tau_{n}^{s}$ の瞬間の変 位と加速度の比の平均值から，その瞬間における角振 動数を

$$
\begin{aligned}
\omega_{(p, n)}^{s} & =\omega_{L 1}+\Delta \omega_{(p, n)}^{s} \\
& =\sqrt{\operatorname{mean}\left(\ddot{V}_{i}\left(\tau_{(p, n)}\right) /-V_{i}\left(\tau_{(p, n)}\right)\right.}
\end{aligned}
$$

と定義する。

この $\tau_{p}^{s}, \tau_{n}^{s}$ における瞬間的な角振動数の線形固有角 振動数からのずれ $\Delta \omega_{p}^{s}, \Delta \omega_{n}^{s}$ とそのときのはり中央の面 外変位 $W_{8 p}^{s}, W_{8 n}^{s}$ の関係を図3に示す。図3には, 式(2) において $\omega^{*}=\omega_{L 1}+\Delta \omega^{*}$ として計算した場合の $\Delta \omega^{*}$ と $W_{8}^{*}$ の関係も同時に示している. また, $\omega_{N L} / \omega_{L 1}=$ $0.871\left(\Delta \omega_{p}^{s} / \omega_{L 1}=0.188, \Delta \omega_{n}^{s} / \omega_{L 1}=-0.307\right)$ のときの $\mathbf{V}_{(p, n)}^{s}$ と, $\Delta \omega_{(p, n)}^{s}$ それぞれと同じ值の $\Delta \omega^{*}$ を用いて 式 $(2)$ を計算した場合の $\mathbf{V}_{(p, n)}^{*}$ を図 4 に示す.これら の図から，式(1)と式(2)の結果は定性的にも定量的に も一致しているといえる. このことから, 式(2)中の 外力パラメータとしての角振動数 $\omega^{*}$ は非線形振動中 に変位と加速度の比がほぼ一定となる時刻における瞬 間的な角振動数に対応しているといえる.また，図5 に示すように, 各非線形固有角振動数における $\tau_{p}^{s}$ と $\tau_{n}^{s}$ における瞬間的角振動数の線形固有角振動数からの ずれの比 $\left|\Delta \omega_{n}^{s} / \Delta \omega_{p}^{s}\right|$ は, 非線形固有角振動数が小さく なると $\left|\Delta \omega_{n}^{s} / \Delta \omega_{p}^{s}\right|$ は 1.5 付近に分布していることがわ かる.
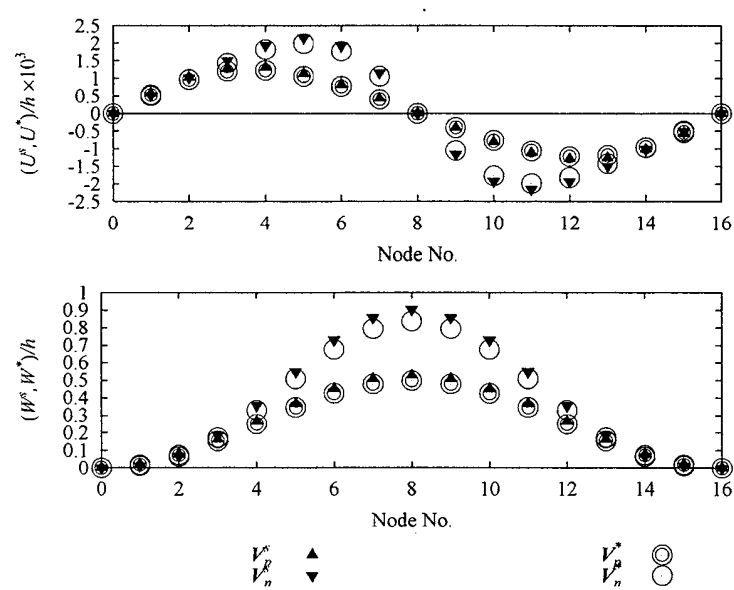

Fig. 4 Distribution of $\mathbf{V}^{s}$ at $\omega_{N L} / \omega_{L 1}=0.871$, and of $\mathbf{V}^{*}$ obtained by $\Delta \omega^{*}=\Delta \omega^{s}$.

\section{3. 低次元化モデルの導出}

以上のことから，本報においては，式(2)におい て $\omega^{*}=\omega_{L 1}+\Delta \omega^{*}$ を用いて計算した解 $\mathbf{V}_{p}^{*}$ と $\omega^{*}=$ $\omega_{L 1}-1.5 \Delta \omega^{*}$ を用いて計算した解 $\mathbf{V}_{n}^{*}$ の奇関数的成分 と偶関数的成分

$$
\begin{aligned}
& \mathbf{V}_{e}^{*}=\left(\mathbf{V}_{p}^{*}-\mathbf{V}_{n}^{*}\right) / 2 \\
& \mathbf{V}_{o}^{*}=\left(\mathbf{V}_{p}^{*}+\mathbf{V}_{n}^{*}\right) / 2
\end{aligned}
$$

を用いて

$$
\mathbf{V}=\mathbf{V}_{o}^{* s} \xi_{o}+\mathbf{V}_{e}^{* s} \xi_{e}+\mathbf{V}_{o}^{* t} \eta_{o}+\mathbf{V}_{e}^{* t} \eta_{e}
$$

と全変数空間から部分空間へ写像することにより低 次元化モデルを得ることとする．ここで，上付き添 え字 $s$ 扔よび $t$ は $s$ 方向成分以外扔よび $t$ 方向成分 以外を 0 としたべクトルであることを示し， $\Delta \omega^{*}$ は $\max \left(\left|W_{8 p}^{*}\right|,\left|W_{8 n}^{*}\right|\right) \simeq 0.5 \mathrm{~h}$ となる值とした. また, $\tau_{p}^{s}$ と $\tau_{n}^{s}$ はおよそ $\pi$ はな扎ていることから, $\bar{\tau}=\tau-\left(\tau_{p}^{s}+\tau_{n}^{s}\right) / 2$ と時間の原点をずらすことにより, $\mathbf{V}_{p}^{s}=\mathbf{V}^{s}\left(\tau=\tau_{p}^{s}\right)=$ $\mathbf{V}^{s}(\bar{\tau}=-\pi / 2), \mathbf{V}_{n}^{s}=\mathbf{V}^{s}\left(\tau=\tau_{n}^{s}\right)=\mathbf{V}^{s}(\bar{\tau}=\pi / 2)$ となる. よって, $\mathrm{V}_{p}^{*}, \mathrm{~V}_{n}^{*}$ には奇関数の奇数次成分と偶関数の偶 数次成分が強く存在していると考えられ， $\mathbf{V}_{p}^{*}, \mathbf{V}_{n}^{*}$ の差 には奇関数の奇数次成分が, 和には偶関数の偶数次成 分が強く存在していると考えられる.

\section{4. 計 算 結 果}

式(1) と写像式(5)によって得られた低次元化モデル に数值積分を適用することによって得られた背骨曲線 を図6に， $\omega_{N L} / \omega_{L 1}=0.871$ における変位空間トラジェ クトリの $U_{1}-U_{2}-U_{4}$ 空間, $U_{5}-U_{6}-U_{7}$ 空間, $W_{1}-W_{2}-W_{4}$ 空 間， $W_{5}-W_{6}-W_{7}$ 空間への射影を図7に示す。これらの図 より，本報で用いた手法により求められた部分空間は 十分に解空間を近似的に内包しているといえ，また， その部分空間への写像によって得られた低次元化モデ ルは, 変位レベルが低い節点においては精度の低下が 見られるが，十分な精度を有するといえる。 


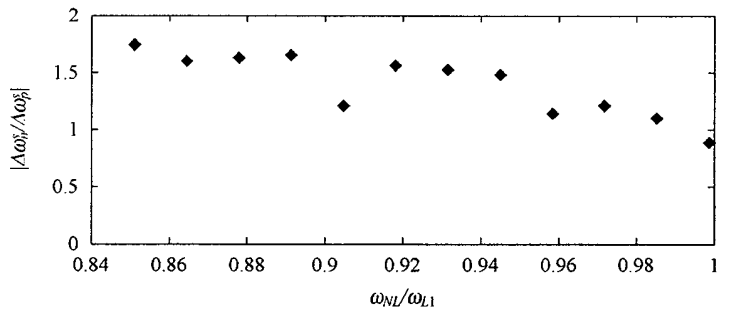

Fig. 5 Absolute value of a ratio of $\Delta \omega_{n}^{s}$ to $\Delta \omega_{p}^{s}$.

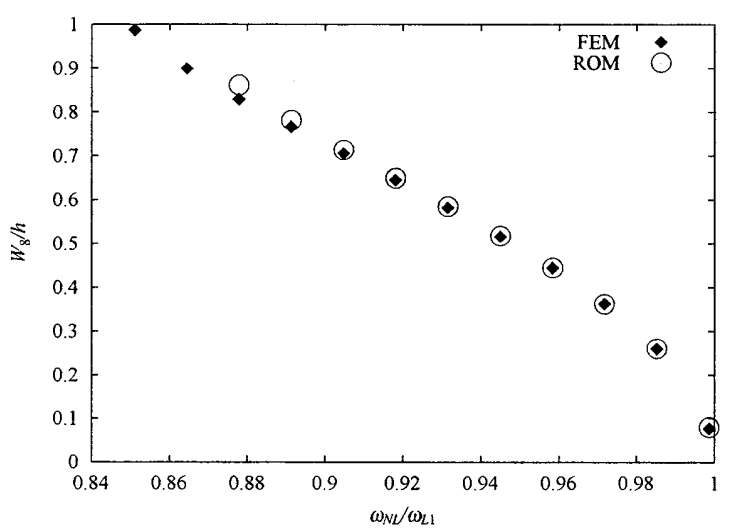

Fig. 6 Back bone curve obtained by the full model (Eq.(1)) and by the reduced order model.

\section{5. よ め}

以上のことから, 静的方程式で用いる等価慣性力の パラメータとしての振動数と動的方程式を解くことに より得られる周期運動の振動数との関係は, 少なくと も本報で扱った対象に対しては，明らかになったとい える.しかしながら，解析の一般化を図る上では，ど のような対象に対してでも半周期離れた時間において 変位と加速度の比がほぼ一定となるような瞬間が生じ るのかを, 理論的に検証する必要があるといえる.

\section{文献}

(1) Yasuda, K., Review of Research in Japan on Nonlinear Oscillation of Elastic Structures, JSME Int. J., 39-3, C (1996), pp.439 - 449.

(2) Ribeiro, P. and Petyt, M., Nonlinear Vibration of Beams with Internal Resonance by Hierarchical Finite-Element Methods, J. Sound Vib., 224-4 (1999), pp.591 - 624.

(3) Shi, Y. and Mei, C., A Finite Element Time Domain Modal Formulation for Large Amplitude Free Vibrations of Beams and Plates, J. Sound Vib., 193-2 (1996), pp.453 -464 .

（4）小林幸徳・山田元・原田晃, 有限要素法を用いた非線 形振動解析の低次元化モデル, 機論, 67-657, C (2001), pp.1330 - 1337.

(5) Harada, A., Kobayashi, Y. and Yamada, G., ReducedOrder Nonlinear Modal Equations of Plates Based on the Finite Element Method, JSME Int. J., 45-1, C (2002), pp.79- 86 .

(6) 原田晃, 真直はりおよび曲がりはりに対する低次元非線 形方程式の導出, D\&D'06 講演論文集, (2006), 講演番号 142.
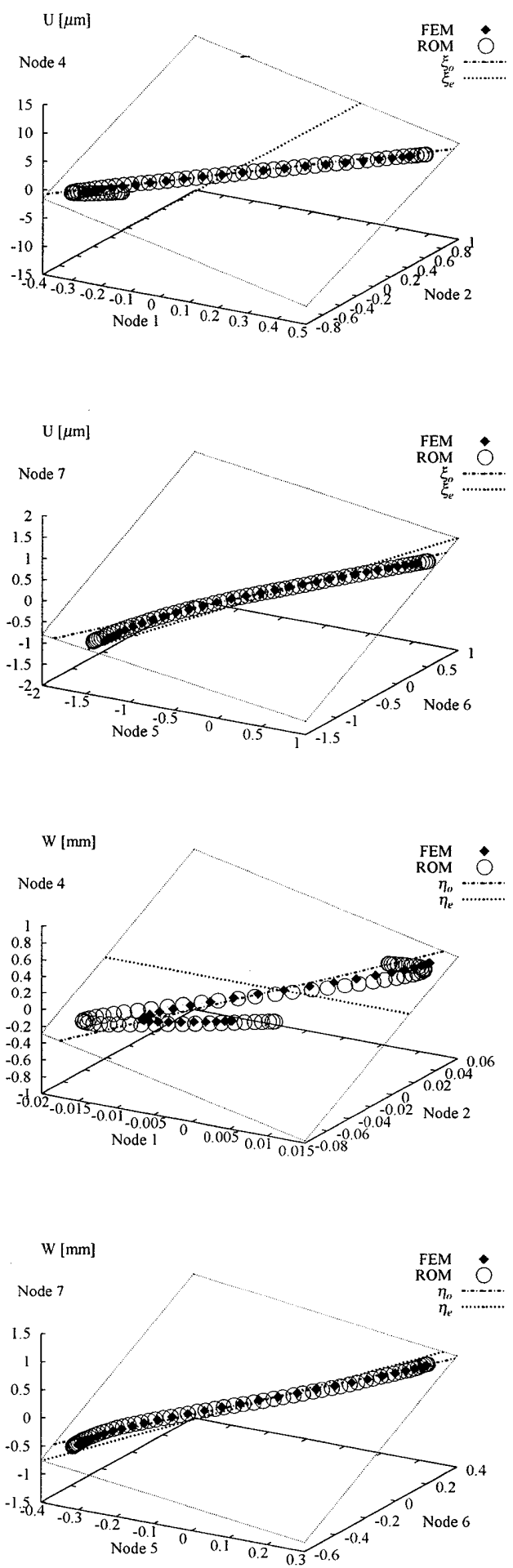

Fig. 7 Trajectory of $\mathbf{V}$ obtained by the full model (Eq.(1)) and by the reduced order model at $\omega_{N L} / \omega_{L 1}=0.871$.

（7）小林幸徳，中林恵市，原田 晃，ばね支持されたはりの 非線形振動解析, 機論, 73-728, C (2007), pp.982 - 988.

(8) 原田晃, 小林幸徳, 擬似モードを用いた曲がりはりの低 次元非線形モード方程式, 機論, 73-728, C (2007), pp.989 $-996$. 